\title{
CHAPADÕES DESCERRADOS: RELAÇÕES ENTRE VEGETAÇÃO, RELEVO E USO DAS TERRAS EM GOIÁS ${ }^{1}$
}

\author{
“CHAPADÕES DESCERRADOS”: RELATIONSHIPS BETWEEN VEGETATION, \\ RELIEF AND LAND USE IN THE STATE OF GOIÁS
}

\section{“CHAPADÕES DESCERRADOS”: LES RELATIONS ENTRE LA VÉGÉTATION, LE RELIEF ET L'UTILISATION DES TERRES DANS L'ÉTAT DE GOIÁS}

\author{
Ivanilton José de Oliveira - Universidade Federal de Goiás - Goiânia - Goiás - Brasil \\ ivanilton.oliveira@gmail.com
}

\begin{abstract}
Resumo
0 artigo apresenta as principais características da vegetação e do relevo no território de Goiás e do Distrito Federal, área core do domínio do Cerrado. Discute suas relações com o processo histórico de ocupação, destacando a rápida e irracional incorporação das terras ao sistema de produção agropecuária, com conversão das fitofisionomias do Cerrado em pastagens e lavouras. Com base na análise de mapeamentos em escala regional, destaca o papel do relevo, que apresenta predominância de terrenos planos e solos profundos, sem grandes restrições à mecanização, e a atividade pecuária como fator decisivo para a transformação das paisagens do Cerrado.
\end{abstract}

Palavras-chave: Cerrado, Goiás, relevo, uso do solo, agropecuária.

\begin{abstract}
This article presents physiographic features (vegetation and relief) of the core area of the Cerrado domain, represented by the territory of the state of Goiás and the Federal District (Brasília). Relations with the historical occupancy process are discussed, highlighting the rapid and irrational incorporation of lands to farm systems, with conversion of the phyto-physiognomies of the Cerrado in pasture and crops. Based on the analysis of mapping on a regional scale, we conclude that relief, with predominantly flat features and deep soils without major constraints to mechanization, was a decisive factor in transforming the Cerrado landscapes.
\end{abstract}

Key words: Cerrado, state of Goiás, relief, land use, agriculture.

\section{Résumé}

Lıarticle présente les principales caractéristiques physiographique (végétation et relief) dans lıÉtat de Goiás et le District Fédéral (Brasilia), qui comprend la zone centrale du Cerrado. Ses relations avec le processus de règlement historique sont discutées, en mettant lraccent sur bintégration rapide et irrationnelle des terres pour le système de production agricole, ce qui a permis la conversion de physionomies du Cerrado dans les pâturages et les cultures. Basé sur lranalyse de la cartographie à lıéchelle régionale, souligne le rôle de relief, surtout de la topographie plane et les sols profonds sans contraintes majeures à la mécanisation, mais ayant le bétail comme un facteur décisif dans la transformation des paysages du Cerrado.

Mots-clés: Cerrado, État du Goiás, relief, I'utilisation des terres, agriculture.

\section{A vegetação dos cerrados}

A definição de variações, nos tipos de vegetação, é um elemento importante para se entender a biodiversidade dos ambientes. Eiten (1979) 
enumera alguns critérios necessários à caracterização de um tipo de vegetação, como o Cerrado, a Floresta Amazônica ou a Mata Atlântica, por exemplo. O primeiro é a fisionomia, utilizada como critério para a classificação de comunidades bióticas, como a distinção de um campo e de uma floresta e que se baseia na aparência dos indivíduos. Nesse sentido, o Cerrado brasileiro assemelha-se à Savana africana. A composição de espécies é outro critério. Distingue-se a Savana africana do Cerrado brasileiro por possuírem espécies totalmente diferentes. Já os condicionantes ambientais (ou condições ecológicas) indicam o papel do meio abiótico (clima, drenagem, relevo, solos). Distinguem, por exemplo, o Cerrado brasileiro da Savana venezuelana, onde o meio abiótico é distinto. É o fator que agrupa, por exemplo, o Cerrado aberto e o Cerrado mais fechado (solos ácidos). A relação entre esses três critérios estabelece a existência de tipos de vegetação, que diferem entre si, em virtude da distinção na fisionomia ou composição de espécies ou condicionantes ambientais.

Um mesmo tipo de vegetação pode ainda apresentar formas distintas, pela diferenciação fisionômica. No caso do Cerrado, distinguem-se formas mais abertas e formas mais fechadas, isto é, há as mesmas espécies e os mesmos condicionantes ambientais, mas fisionomicamente são diferentes. De acordo com Eiten (1979), em classificações de formas, são consideradas a estrutura, como a altura e a densidade das diferentes camadas (arbórea, arbustiva e rasteira); a mudança do aspecto vegetativo durante o ano, como a caducidade, a estacionalidade; a forma de crescimento dos indivíduos e, em alguns sistemas, a consistência e o tamanho das folhas. Para o autor, em outro trabalho (Eiten, 1993), o Cerrado é relacionado ecológica e fisionomicamente às savanas e aos arvoredos mais úmidos e distróficos de outros continentes, com chuvas no verão, como o "miombo" e outros arvoredos relacionados ao sul da África, e os arvoredos e savanas de Eucalyptus no norte da Austrália.

A palavra savana tem sua provável origem associada à designação dada pelos espanhóis, em 1503, a uma vegetação encontrada na Venezuela. A adoção desse termo, para a identificação do Cerrado brasileiro (como fizeram os pesquisadores do Projeto Radambrasil), também não é consenso entre a comunidade científica, embora se reconheça a validação internacional da terminologia.

Quanto ao ambiente do Cerrado, a nomenclatura mais adequada para a sua definição também parece não ser consenso entre os pesqui- 
sadores, visto que existem diversas referências a ele, tais como província vegetacional (Eiten, 1993), sistema biogeográfico (Barbosa, 1996), domínio fitogeográfico (Ab’Saber, 1971), bioma (Dias, 1993; Alho, 1993; Alho; Martins, 1995; Ribeiro; Walter, 1998) e, ainda, região fitoecológica (Magnago; Silva; Fonzar, 1983).

Originalmente, a área recoberta pelo domínio do Cerrado cobria cerca de 2 milhões de quilômetros quadrados, o que representava quase 1/4 do território brasileiro. Sua área incluía todo o estado de Goiás e o Distrito Federal, a maior parte do Tocantins e do Mato Grosso do Sul, o centro e o sul do Mato Grosso e do Maranhão, o oeste da Bahia e de Minas Gerais, o noroeste de São Paulo, o sul do Piauí e uma faixa em Rondônia. De maneira disjunta, ocorre (ou ocorria) também no Paraná, no norte de São Paulo e como encraves em meio à Caatinga no Nordeste e na Floresta Amazônica.

\section{A vegetação original de Goiás e do Distrito Federal}

As áreas somadas do Distrito Federal e do estado de Goiás chegam

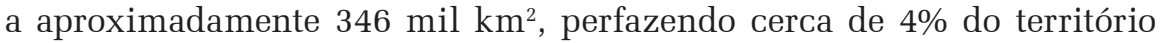
brasileiro. Localizadas na região mais central do Brasil, essas terras eram, originalmente, recobertas pelo domínio do Cerrado, mas com a presença significativa de outros tipos vegetacionais (Figura 1), dependendo das variações nos condicionantes ambientais, como as altitudes, os tipos de solos e a dinâmica climática.

Em terras goianas e brasilienses, o domínio do Cerrado apresenta, em sua fisionomia, variações que vão de formas florestadas (matas secas, de galeria ou ciliares) até formações tipicamente campestres (campos sujos, limpos ou rupestres), cujos limites nem sempre são bem definidos. Além das formações savânicas características do domínio, incorpora também outros tipos de vegetação com pouca expressividade espacial, mas ecologicamente muito importantes, como as veredas e os palmeirais. A Tabela 1 apresenta a área originalmente ocupada pelos principais tipos fitofisionômicos no território de Goiás e do Distrito Federal. 


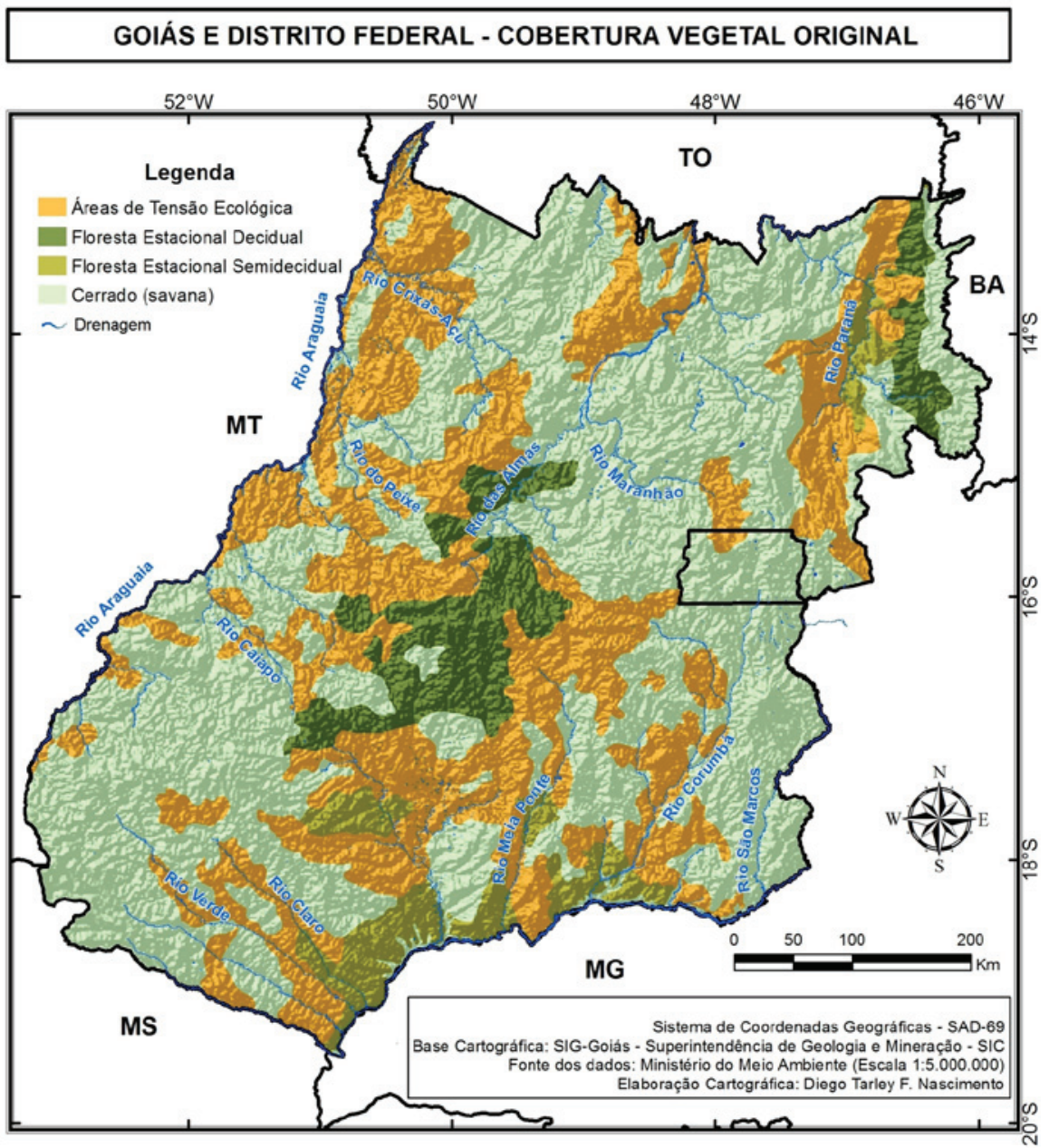

Figura 1 - Mapa da vegetação original no estado de Goiás e no Distrito Federal.

Observa-se, de forma clara, o domínio das formações fitofisionômicas classificadas como Cerrado (savana). Mais da metade do território era originalmente recoberta pelas fisionomias campestres, arbustivas, arbóreas e florestadas de Cerrado. As áreas de transição (tensão ecológica) entre o Cerrado e as florestas também eram significativas, compondo quase um terço do território. É preciso atentar para o fato de que, na escala apre- 
sentada, a classe identificada como "Cerrado" incorpora manchas, ilhas e corredores de outros tipos de vegetação como, por exemplo, as florestas de galeria e as matas secas.

Tabela 1 - Vegetação original do território do estado de Goiás e do Distrito Federal.

\begin{tabular}{l|c|c}
\hline Tipo de vegetação & Área em $\mathrm{km}^{2}$ & \% da área total \\
\hline Cerrado & $192.729,82$ & 55,54 \\
\hline Floresta Estacional Decidual & $24.418,24$ & 7,04 \\
\hline Floresta Estacional Semidecidual & $16.446,60$ & 4,74 \\
\hline Áreas de Tensão Ecológica & $111.896,93$ & 32,25 \\
\hline Não classificadas (ou sem vegetação) & $1.523,50$ & 0,44 \\
\hline Total & $345.890,00$ & 100,00 \\
\hline
\end{tabular}

Fonte: Cálculo obtido em SIG.

O número e a definição de tipos diferentes de vegetação e de fitofisionomias do Cerrado também variam dependendo das classificações adotadas. Eiten (1979) enumera estas cinco formas como as mais expressivas: cerradão, cerrado (sentido restrito), campo cerrado, campo sujo e campo limpo. O próprio autor, entretanto, considera que uma classificação mais detalhada seria útil ao reconhecimento dos aspectos da vegetação, inclusive para facilitar o uso dos mesmos termos em outros idiomas.

Magnago, Silva e Fonzar (1983) utilizaram o termo savana, usado nos trabalhos do Projeto Radambrasil, apresentando as seguintes variações: savana arbórea densa, savana arbórea aberta com ou sem floresta de galeria, savana parque com ou sem floresta de galeria e savana gramíneo-lenhosa com ou sem floresta-galeria. O IBGE (2012) estabelece uma correlação entre essas denominações e aquelas típicas do Cerrado: a savana arbórea densa, grosso modo, equivale ao cerradão; a savana arbórea é equivalente ao cerrado stricto sensu e ao campo cerrado; a savana parque é o campo sujo de cerrado; e a savana gramíneo-lenhosa equivale ao campo limpo de cerrado. $\mathrm{O}$ aspecto dessas diferentes fitofisionomias é apresentado na Figura 2. 


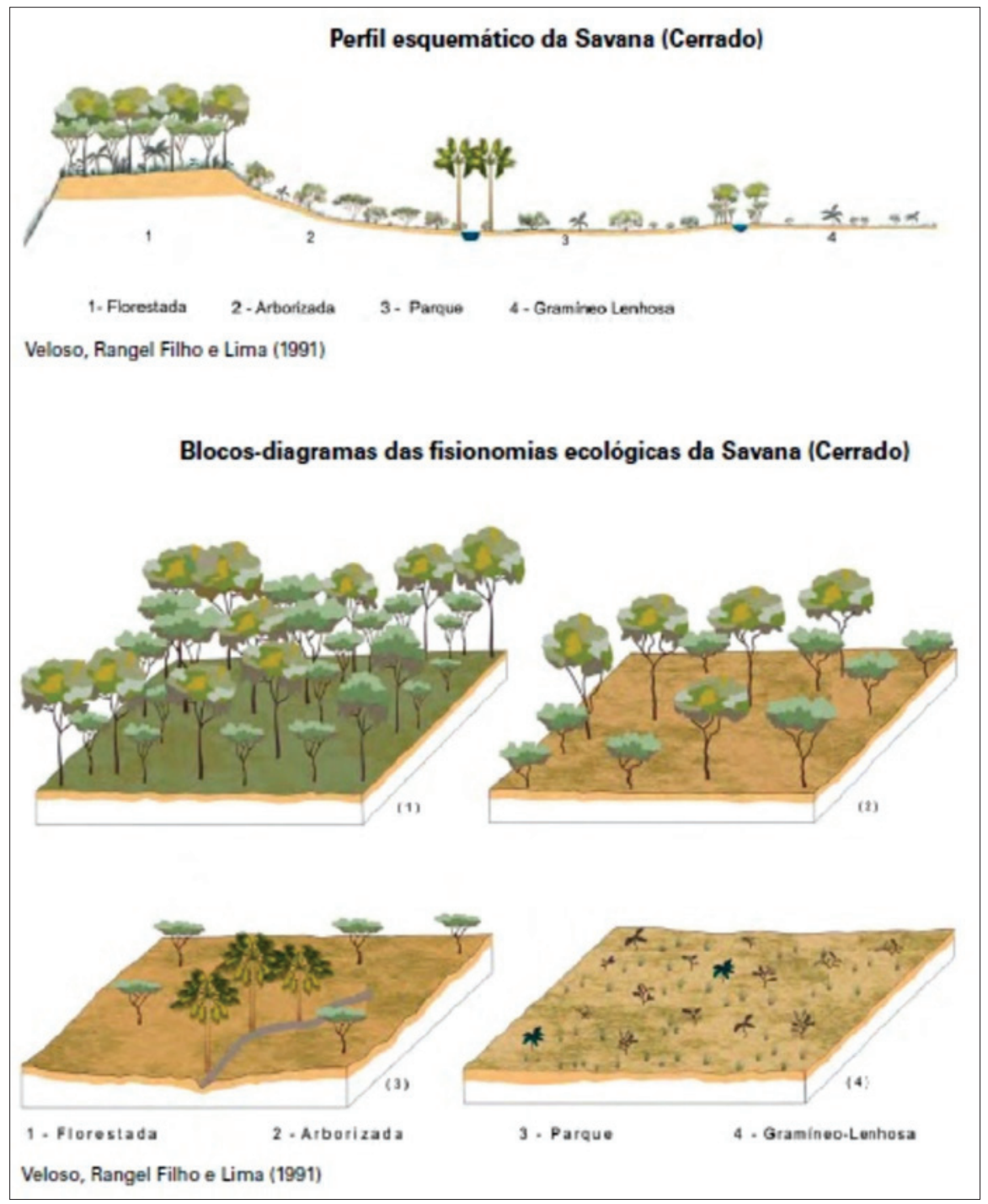

Figura 2 - Fitofisionomias do Cerrado.

Fonte: IBGE, 2012 (adaptado).

Walter, Carvalho e Ribeiro (2008, p. 40), no entanto, embora concordem com o fato de o Cerrado ser uma savana, explicam que é preciso dissociar certas fitofisionomias, que não são savânicas, a exemplo do cer- 
radão, que deve ser classificado como uma floresta, ou do campo limpo, identificado como um campo puro.

O aspecto das formas mais usuais existentes no domínio do Cerrado varia conforme os condicionantes ambientais. Os principais tipos de vegetação são classificados entre formações florestais, formações savânicas e formações campestres (Figura 3). Todas essas variações ainda são encontradas no território goiano-brasiliense, embora sua área tenha sido reduzida drasticamente.

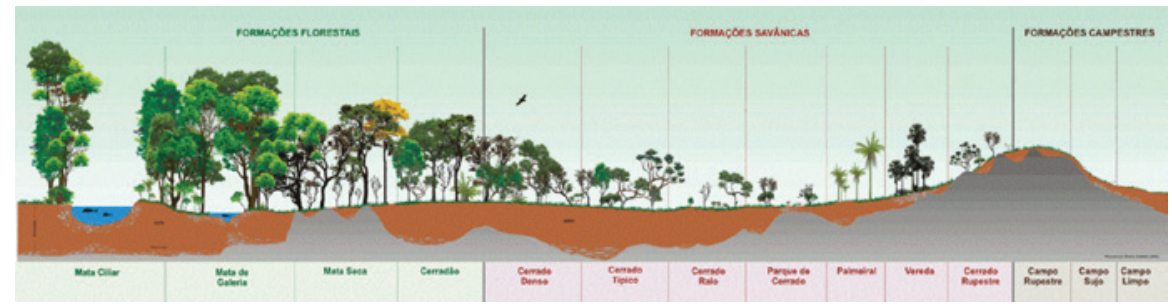

Figura 3 - Fitofisionomias que ocorrem no domínio do Cerrado.

Fonte: Ribeiro; Walter, 2008 (adaptado).

Dentre as formações savânicas do Cerrado, Ribeiro e Walter (2008) identificam quatro tipos principais: o Cerrado sentido restrito, a Vereda, o Palmeiral e o Parque de Cerrado.

O Cerrado sentido restrito (stricto sensu), de acordo com Ribeiro e Walter (2008, p. 176), é considerado uma formação predominantemente arbórea ou arbóreo-arbustiva, com cobertura arbórea variando de 5\% a $70 \%$ e a altura média das árvores variando de 2 até 8 metros. Para os autores, a densidade arbóreo-arbustiva ou o ambiente permitem identificar até quatro subtipos: cerrado denso, cerrado típico, cerrado ralo e cerrado rupestre. Enquanto as três primeiras refletem variações na densidade de árvores, a última está associada a um substrato rochoso. O Cerrado sentido restrito ocorria em extensas manchas por todo o estado de Goiás e Distrito Federal, com a fitofisionomia dominante; na atualidade restam poucos remanescentes com dimensão significativa.

Dentre as formações savânicas, a Vereda é o segundo tipo mais fortemente associado à imagem atual do Cerrado; isso se deve, em grande parte, à sua beleza cênica. Em geral, ocorre nos fundos de vales e em cabeceiras de drenagem, onde o chão é permanentemente brejoso, com lençol 
freático aflorante ou muito próximo à superfície. É marcante a presença dos buritis (Mauritia flexuosa) ou, ao norte, da buritirana (Mauritiella armata), ladeados por campo graminoso úmido. Sua distribuição geográfica é dispersa pelo estado de Goiás e Distrito Federal.

O Parque de Cerrado apresenta ocorrência de árvores concentrada em pequenas elevações do terreno, conhecidas como "murundus", "covais" ou "monchões", que são ladeados por formações herbáceas nas depressões comumente alagadas nos períodos chuvosos. Ao contrário das veredas, a distribuição geográfica dos Parques de Cerrado é concentrada e foram identificados apenas em algumas áreas do sudoeste de Goiás e no Distrito Federal.

Os Palmeirais, de acordo com Ribeiro e Walter (1998), são caracterizados pela presença marcante de uma única espécie de palmeira arbórea, colonizando terrenos bem ou mal drenados. Dependendo da espécie dominante, podem ser denominados "macaubal" (Acrocomia aculeata), "guerobal” (Syagrus oleracea), "babaçual” (Attalea speciosa) ou "buritizal" (Mauritia flexuosa ou Mauritiella armata). Gomes, Teixeira Neto e Barbosa (2004, p. 147) afirmam que os palmeirais ocorrem em Goiás, sobretudo no vale do rio Maranhão (norte do estado) e nas vertentes do rio Araguaia, com manchas importantes também na Chapada dos Veadeiros.

Dentre as formações campestres existentes no domínio do Cerrado, Ribeiro e Walter (2008, p. 83) identificam três tipos fitofisionômicos principais: o Campo Sujo, o Campo Limpo e o Campo Rupestre.

O Campo Sujo apresenta o domínio de gramíneas com a presença de arbustos e árvores anãs, em geral, indivíduos menos desenvolvidos das formações savânicas do Cerrado. Para Ribeiro e Walter (1998), as variações ambientais podem dar origem a subformações, como "campo sujo seco” (lençol freático baixo), “campo sujo úmido” (lençol freático alto) e "campo sujo com murundus" (existência de microrrelevos mais elevados, onde crescem as árvores). A ocorrência do campo sujo ainda é especialmente marcante no norte e noroeste do estado de Goiás, na depressão do rio Araguaia.

Já o Campo Limpo apresenta um único estrato de gramíneas com folhagens que não as ultrapassam em altura. Trata-se de um estrato herbáceo ou subarbustivo despojado de árvores e arbustos que pode ter as mesmas variações fisionômicas apresentadas pelo campo sujo. Os campos limpos úmidos são também chamados de campos estacionais ou várzeas. 
Ocupavam grandes extensões nos chapadões do sudoeste goiano e nas depressões do Araguaia e do Tocantins.

Com relação ao Campo Rupestre, trata-se de uma fitofisionomia predominantemente herbáceo-arbustiva, com eventuais árvores de pequeno porte. Desenvolve-se em altitudes superiores a 900 metros, sobre afloramentos rochosos. Apresenta forte endemismo e plantas raras (Ribeiro e Walter, 1998). Em Goiás, ainda é comum na Serra Dourada, na Serra dos Pirineus e na Chapada dos Veadeiros.

E, por fim, dentre as formações florestais presentes no domínio do Cerrado, estão o Cerradão, a Mata Seca, a Mata Ciliar e a Mata de Galeria.

De acordo com Ribeiro e Walter (2008, p. 172), o Cerradão é uma formação florestal com característica esclerófila. Ou seja, do ponto de vista fisionômico, é uma formação florestal, embora floristicamente seja mais similar a um Cerrado sentido restrito. Apresenta árvores com altura média entre 8 e 15 metros, com as copas se tocando (cobertura entre 50 e 90\%, de acordo com Ribeiro e Walter, 1998) e um estrato herbáceo/subarbustivo pobre e rarefeito. Sua ocorrência no território goiano era disseminada, com manchas expressivas em meio às formações abertas de Cerrado e, também, entre as áreas de tensão ecológica, na transição para as florestas.

A Mata Seca inclui as formações florestais não associadas a cursos d'água e, conforme Pereira, Venturoli e Carvalho (2011), equivale ao tipo identificado como Floresta Estacional na classificação adotada pelo Projeto Radambrasil (Magnago; Silva; Fonzar, 1983). Constitui--se de matas relacionadas aos solos mais ricos em nutrientes. A composição de espécies é bastante distinta daquela do Cerrado sentido restrito e a altura média do estrato arbóreo varia entre 15 e 25 metros, com dossel fechado na época chuvosa. É descrita como Decidual ou Semidecidual, em virtude de sua estreita relação com a estacionalidade climática e com o percentual de espécies que perdem as folhas (caducifólias) na estação seca. Ribeiro e Walter (1998) utilizam os termos Mata Seca "sempre-verde", quando a cobertura arbórea se mantém entre $60 \%$ e $90 \%$ mesmo na estiagem (perenifólia); "semidecídua”, quando essa cobertura fica entre 50\% e 60\% (subcaducifólia); e "decídua", quando os percentuais ficam entre 30\% e 50\%. Sua ocorrência nas encostas dos vales, em razão da maior fertilidade dos solos que nos topos planos, é também denominada de floresta de encosta ou submontana. 
A Mata Ciliar é também bastante característica em ambientes do domínio do Cerrado; em geral, ocorre sobre terrenos acidentados, em meio às formações savânicas ou campestres, acompanhando os rios mais largos. Segundo Ribeiro e Walter (2008, p. 164), trata-se de uma formação de aspecto semidecíduo, floristicamente similar à Mata Seca, com árvores que atingem de 20 a 25m. Já a Floresta de Galeria, também chamada de mata de galeria, é um tipo de vegetação perenifólia, floristicamente distinta da Mata Ciliar. Apresenta dossel fechado sobre a drenagem e a altura média do porte arbóreo varia entre 20 e 30 metros.

Extensos trechos da cobertura vegetal nativa, especialmente no centro-sul, noroeste e nordeste do estado de Goiás foram mapeados como áreas de tensão ecológica, representando a ocorrência da transição de tipos fitofisionômicos do Cerrado para a Floresta Amazônica ou para a Mata Atlântica. Nesses locais de contato entre os domínios fitoecológicos, os tipos vegetacionais ocorrem (ou ocorriam) como encraves, ora sob o domínio das formações savânicas, ora das formações florestadas.

Convém ressaltar que, como destaca Coutinho (1992), as várias formações do domínio do Cerrado não se apresentam ordenadas dessa maneira, mas sim como um grande mosaico de vegetação, em que se alternam e se mesclam as fisionomias de campo, as savânicas e as florestais, como reflexo da distribuição das manchas de solo, da incidência irregular das queimadas e de outras formas de ação antrópica.

Para Eiten (1993), o efeito do clima (sazonalidade) sobre o Cerrado, por exemplo, é direto pelo fato de que o Cerrado só existe onde não há geadas ou, como na borda sul da província, onde ocorrem somente geadas infrequentes, quase sempre leves e de pouca duração. De acordo com o autor, dentro desses limites, o efeito do clima sobre o Cerrado é indireto, por meio da sua ação sobre o solo, lixiviando as partes superficiais e mudando os minerais de argila para tipos que retêm poucos íons. Dessa maneira, quase todo o solo de interflúvio no Brasil Central é pobre em íons nutrientes e assim sustenta o Cerrado, condicionando o que se considera um "clímax edáfico", mesmo que fosse o clima, agindo sobre o tempo geológico, que deu estas características ao solo.

O aspecto xeromorfo das plantas do Cerrado - que apresentam estrutura semelhante à das plantas xerófitas, adaptadas à escassez de água - também tem uma relação direta com os condicionantes ambientais. Uma das teorias que buscam explicar essa peculiaridade do Cerrado é a do 
escleromorfismo oligotrófico, de Karl Arens (1958). As plantas, na fotossíntese, sintetizam como primeiro elemento a glicose (com seis átomos de carbono), daí elas precisarem do carbono (presente no gás carbônico absorvido pela respiração), oxigênio (presente na água) e luz. De acordo com esse autor, na região do Cerrado, há luz abundante e não há escassez de água porque as plantas (nem todas as espécies) possuem raízes profundas. Algumas recorrem ainda a certos mecanismos nos períodos secos, como a perda das folhas. Ou seja, as plantas sintetizam carboidratos sem problemas, mas na hora de sintetizar as proteínas não dispõem de minerais suficientes. Por isso, não crescem suficientemente e apresentam a aparência esclerosada - pelo carboidrato acumulado como reserva nos caules e galhos.

A flora nativa do Cerrado está adaptada a esses solos pobres, ditos distróficos ou oligotróficos, inclusive com alta resistência ao elevado teor de alumínio trocável, extremamente tóxico a outras plantas. Para Coutinho (1992), o efeito do fogo também é marcante na caracterização fisionômica do Cerrado. As queimadas afetam, sobretudo, o estrato arbóreo/ arbustivo, menos adaptado que o estrato herbáceo/subarbustivo. Assim, quando submetidos a queimadas frequentes, os cerradões acabam por se abrir e se transformar em campos sujos ou campos limpos. Ab'Saber e Costa Jr. (1950) notaram tal relação, em observação realizada no sudoeste goiano, e afirmam que as atividades de pastoreio e seu sistema de queimadas teria contribuído para modificar o quadro da vegetação original. Os cerradões teriam se transformado em cerrados e cerradinhos, assim como capões de mata em tipos degradados de vegetação.

\section{Caracterização geral do relevo}

Existem várias formas de se representar o relevo. Os mapas geomorfológicos procuram representar uma visão sintética do relevo, a partir de elementos de suas formas (morfografia), de sua gênese e processos atuantes (morfogênese), das idades (geomorfocronologia) e também de seus parâmetros métricos (morfometria), como as altitudes, as declividades, o grau de dissecação, as medidas dos interflúvios, entre outros. Uma das representações mais comuns do relevo é o mapa que retrata a hipsometria, ou seja, as diferentes faixas de altitudes encontradas numa determinada região. As altitudes são um elemento importante na compreensão do re- 
levo e como ele influencia alguns dos outros componentes da paisagem, como a vegetação e o clima. As alterações de altitude determinam mudanças marcantes nos valores de temperatura do ar atmosférico, chegando mesmo a criar condições climáticas muito distintas daquelas que deveriam ocorrer numa determinada faixa de latitude.

Como se sabe, as características climáticas estão intimamente associadas às variações de latitude. Grosso modo, quanto mais próximos das baixas latitudes (da Linha do Equador), mais altas são as temperaturas. E quanto mais nos afastamos da região equatorial e nos aproximamos dos polos (altas latitudes), mais baixas tendem a ser as temperaturas. Contudo, a elevação em altitude também provoca alterações na temperatura. Assim, relevos mais altos apresentam temperaturas mais baixas que relevos mais baixos, numa mesma faixa de latitude.

Como os componentes do clima são interligados, isso significa que alterações na temperatura do ar também provocam mudanças nos demais índices, como a pressão atmosférica, a umidade e mesmo a circulação das massas de ar. Essas oscilações das características climáticas, relacionadas às mudanças no perfil altimétrico do relevo, levam também à influência no desenvolvimento da cobertura vegetal.

As plantas são extremamente sensíveis às variações dos elementos do clima, especialmente da temperatura e dos índices pluviométricos. Tanto que as grandes regiões fitogeográficas tendem a apresentar contornos majoritariamente zonais, que acompanham as faixas de latitude no planeta. Outro exemplo claro dessa relação é que, mesmo com todo o avanço tecnológico no desenvolvimento de variedades de plantas, ainda há uma dependência estreita entre a agricultura e as condições climáticas. Assim, conhecer as variações de altitude - a hipsometria - de um lugar permite inferir também os elementos do clima e, assim, de seu reflexo na distribuição da cobertura vegetal e das formas de uso e ocupação das terras.

Já as variações de declividade do relevo - suas inclinações em relação a um perfil horizontal - nos dão indicadores importantes quanto às possibilidades e restrições de sua ocupação. As declividades influem diretamente na distribuição dos tipos de solos. Em geral, quanto mais planos os terrenos, maior a tendência de predomínio da pedogênese (a formação de solo) em relação à morfogênese (o desgaste ou esculturação do relevo). Dessa forma, enquanto as áreas planas tenderiam a formar 
solos profundos, pela maior probabilidade de infiltração da água das chuvas e sua ação na decomposição das rochas, as áreas com relevo mais movimentado tenderiam a formar solos rasos ou nem mesmo permitir a sua formação, já que a força da gravidade aumentaria o transporte dos materiais fragmentados ou decompostos.

Claro que essa relação pedogênese-morfogênese também é influenciada por outros fatores. O clima e a presença ou ausência de cobertura vegetal são alguns deles. Contudo, a simples variação das declividades promove também variações na distribuição dos tipos de solos, que refletem, ainda, seu material de origem, a partir de sua composição mineralógica e de seu grau de fertilidade que influem diretamente na distribuição da vegetação. Assim, solos mais férteis, por exemplo, tendem a permitir o desenvolvimento de uma vegetação mais densa e de maior porte, como as florestas.

\section{0 domínio dos chapadões e das depressões}

Em Goiás, uma característica marcante do relevo são as extensas áreas planas ou suavemente onduladas, que dominam as paisagens em quase todas as regiões do estado, com variações altimétricas que vão desde menos de $200 \mathrm{~m}$ até pouco mais de $1.600 \mathrm{~m}$, como pode ser visto no mapa da Figura 4, elaborado com base no processamento de imagens do Space Shuttle Radar Topography Mission (SRTM).

Em um passeio aéreo sobre o território goiano, vemos, a sudoeste, extensos chapadões e chapadas, que chegam a mais de $1.000 \mathrm{~m}$ de altitude (Figura 4), muitas vezes interrompidos por desníveis estruturais, como escarpas oriundas de antigas falhas. Indo em direção ao Vale do Araguaia, no oeste-noroeste de Goiás, a paisagem lembra uma escadaria em declive, a partir da Serra do Caiapó (uma cuesta), para os níveis mais baixos e extremamente planos da Depressão do Araguaia, com altitudes entre menos de $300 \mathrm{~m}$ e cerca de $400 \mathrm{~m}$. Seguindo o curso do rio, chegamos às belas paisagens de acúmulo fluvial, marcadas pelas extensas faixas de areia e lagos de meandros abandonados que bordejam o médio Araguaia, com altitudes inferiores a $200 \mathrm{~m}$. 


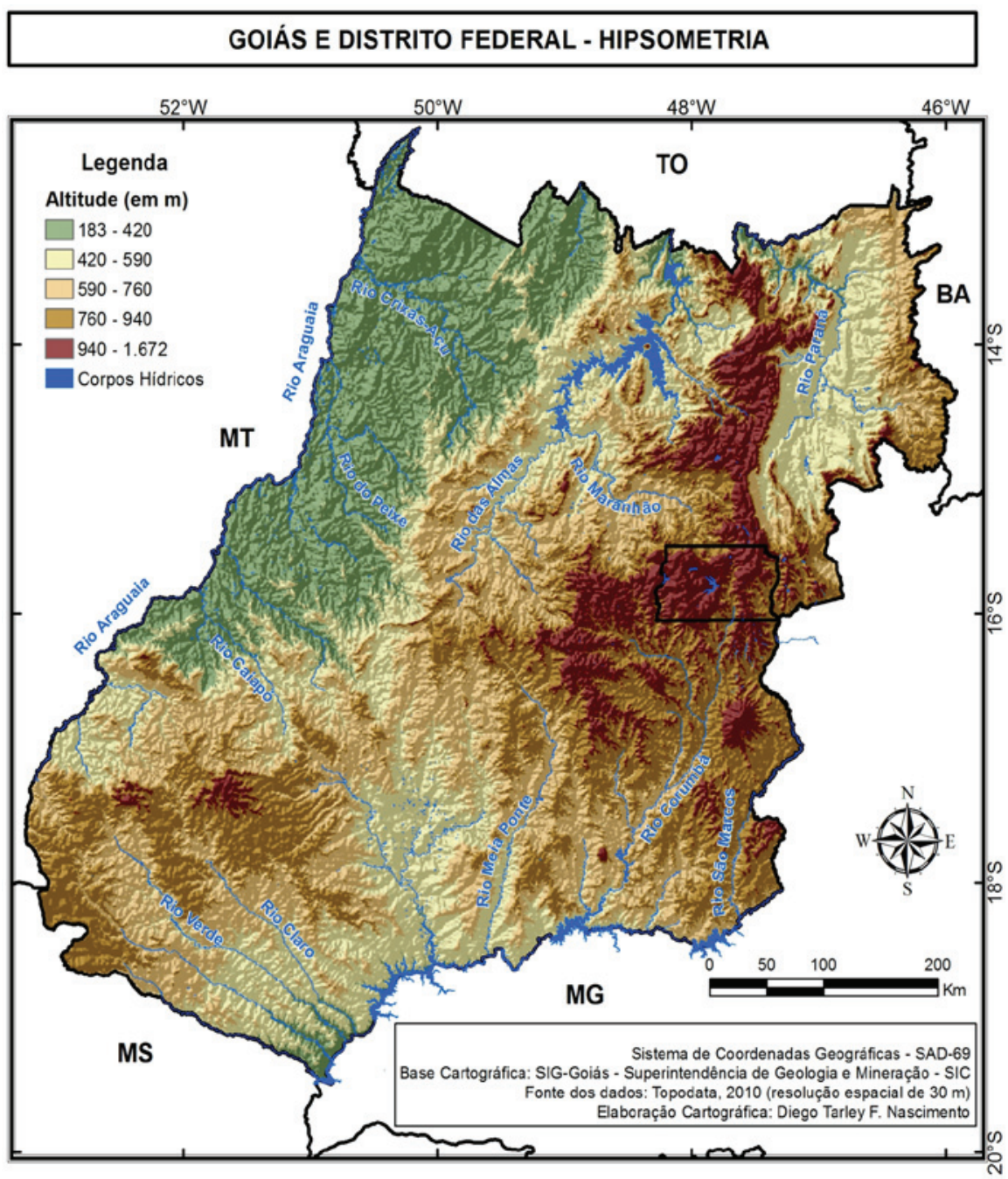

Figura 4 - Mapa hipsométrico do território de Goiás e Distrito Federal.

Nos limites com o estado do Tocantins, direcionando-se para o leste, encontramos, a aproximadamente 200 quilômetros de distância, uma sequência de relevos residuais mais elevados (no local, chamados de serras, como ocorre com quase todas as elevações mais marcantes de Goiás), em meio aos terrenos muito planos e baixios (abaixo de 600m) que 
acompanham o sentido dos afluentes do rio Tocantins, como o rio das Almas e o rio Maranhão. Essas depressões são interrompidas por uma elevação gradual, mas em alguns pontos brusca, até atingir a Chapada dos Veadeiros, que guarda as maiores altitudes do estado e ultrapassa, em alguns locais, os $1.600 \mathrm{~m}$; ali se encontra o ponto mais alto de Goiás, conhecido como Pouso Alto, a 1.672m de altitude.

A Chapada dos Veadeiros é o topônimo mais conhecido das terras altas goianas e faz parte de um imenso planalto que se estende majestoso pelo norte-nordeste goiano, formando uma faixa contínua em direção ao centro e ao sudeste do estado. Ao leste, ela é interrompida bruscamente por um declive, que leva ao Vão do Paranã, outra região marcante do relevo goiano. Essa depressão, com altitudes em torno de 450m, é drenada pelo rio Paranã e seus afluentes e bordejada a leste pela escarpa do Chapadão Central (BA), que constitui a Serra Geral de Goiás (Nascimento, 1992). Forma uma faixa de sentido norte-sul, conectando-se, ao norte, com as depressões do rio Tocantins. Ao sul, ela vai ganhando altitude até dar lugar ao Planalto do Distrito Federal, uma imensa sequência de chapadões que domina o leste de Goiás (e o território do Distrito Federal), com altitudes superiores a $1.200 \mathrm{~m}$.

Indo do Planalto do Distrito Federal em direção a Goiânia, no centro do estado, as altitudes vão diminuindo gradativamente, para ficar entre 700 e 900m. Essa região, denominada de Planalto Rebaixado de Goiânia (Nascimento, 1992; Mamede, 1993), atua como uma área de conexão entre os níveis altimétricos mais elevados do leste e do sudoeste de Goiás, representando a zona de esculturação do relevo pelos tributários da margem direita do alto curso do rio Paranaíba. No extremo sul do estado, esse planalto apresenta altitudes predominantes entre 300 e 400m.

Esse "voo" virtual sobre o relevo goiano terminaria sobre o sudoeste, como já mencionado, uma região marcada pelos chapadões extensos e pelas chapadas residuais, de orientação grosseiramente noroeste-sudeste, fruto da dissecação dos rios (e seus afluentes) que correm quase paralelamente para o Paranaíba, sobre o reverso da Cuesta do Caiapó, borda noroeste da bacia sedimentar do Paraná.

A hipsometria do território de Goiás e Distrito Federal apresenta, como visto, marcante contraste entre os compartimentos geográficos. A Tabela 2 apresenta os resultados do cálculo de área para cada faixa de altitude. 
Tabela 2 - Hipsometria do estado de Goiás e do Distrito Federal.

\begin{tabular}{c|c|c}
\hline Faixa de altitude (m) & Área $\mathbf{~} \mathbf{~ k m}^{\mathbf{2}}$ & \% da área total \\
\hline 183 a 420 & 66.765 & 19,3 \\
\hline 420 a 590 & 81.977 & 23,7 \\
\hline 590 a 760 & 90.823 & 26,3 \\
\hline 760 a 960 & 75.365 & 21,8 \\
\hline 960 a 1.672 & 30.960 & 9,0 \\
\hline Total & 345.890 & 100,0 \\
\hline
\end{tabular}

Fonte: Cálculo obtido em SIG, tendo por base imagens SRTM.

Vislumbra-se uma sequência de faixas de sentido sudoeste-nordeste, opondo, por exemplo, o sul, o oeste e o noroeste do estado, com as menores altitudes, ao sudoeste, sudeste, centro-leste e nordeste (à exceção do Vão do Paranã), com as maiores altitudes. Essa característica é determinante na função do território goiano como grande divisor de águas de algumas das maiores bacias hidrográficas do país. O arco de elevações, que se inicia no sudoeste e continua em direção ao centro, onde bifurca para o norte e para o sudeste, faz com que os cursos d'água corram, a oeste e norte, para a bacia hidrográfica do Araguaia-Tocantins (considerada, por alguns, como parte da bacia Amazônica); ao sul, para a bacia do Paranaíba (integrante da bacia Paraná-Uruguai); e ainda para a bacia do São Francisco, no caso de alguns rios ao leste.

Quanto às declividades, o mapa elaborado também com base nas imagens SRTM demonstra um predomínio dos terrenos planos em quase todo o estado (Figura 5). Na sequência, a Tabela 3 mostra o cálculo de área $\left(\mathrm{em} \mathrm{km}^{2}\right.$ ) das classes de declividade, além da tipologia de formas do relevo (plano, suave ondulado etc.) indicada para cada faixa nos trabalhos do Projeto Radambrasil (Novaes et al., 1983).

O mapa clinográfico indica um predomínio absoluto das declividades entre 0 e $3 \%$, que, somados, correspondem a pouco mais de $80 \%$ do território de Goiás e do Distrito Federal. Essa faixa de declividades apresenta um aspecto disperso por toda a região, embora sua expressividade como mancha contínua seja marcante no oeste e noroeste de Goiás, correspondente à Depressão do Araguaia, e no nordeste do estado, na área do chamado Vão do Paranã. 


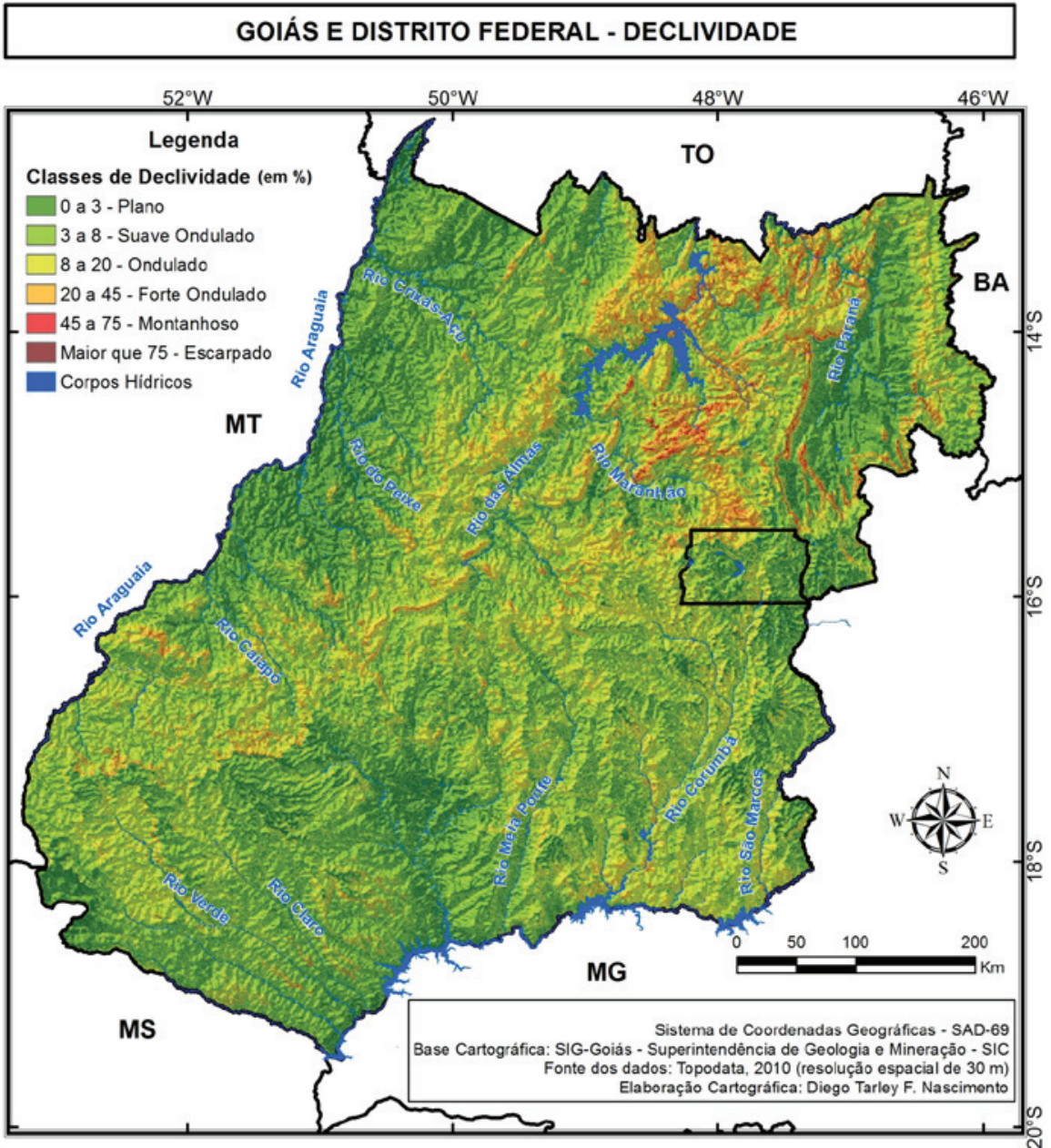

Figura 5 - Mapa clinográfico do território de Goiás e Distrito Federal.

Observa-se claramente um corredor de declividades mais pronunciadas cortando o território goiano numa diagonal sudoeste-nordeste, em clara relação com o arco de elevações referido anteriormente. Nas regiões a sudoeste e sul, as maiores declividades representam os alinhamentos 
das escarpas erosivas, fruto do trabalho de esculturação dos rios tributários do Paranaíba, daí o sentido noroeste-sudeste.

Tabela 3 - Declividades no estado de Goiás e no Distrito Federal.

\begin{tabular}{c|l|r|r}
\hline Classe $(\%)$ & Tipologia $^{(1)}$ & Área $\mathrm{em}^{2}$ & $\%$ da área total \\
\hline 0 a 3 & Plano & $279.273,62$ & 80,48 \\
3 a 8 & Suave ondulado & $40.998,76$ & 11,81 \\
8 a 20 & Ondulado & $20.962,16$ & 6,04 \\
20 a 45 & Forte ondulado & $5.501,81$ & 1,59 \\
45 a 75 & Montanhoso & 250,01 & 0,07 \\
$>75$ & Escarpado & 28,72 & 0,01 \\
\hline Total & & $347.015,09$ & 100,00 \\
\hline
\end{tabular}

Fonte: Cálculo obtido em SIG, a partir da geração de uma grade irregular triangular (TIN) e seu fatiamento, tendo por base as imagens SRTM.

(1) Conforme indicado por Novaes et al. (1983).

Ao norte, aparecem as mais expressivas manchas de declividades acima de $20 \%$ ou mesmo $45 \%$. Carvalho (2003) afirma que elas formam "diversas faixas pouco espessas, de sentido predominantemente norte-sul, que parecem, em certo momento, constituir um caldeirão 'caótico' naquela região”. Isso espelharia, nas palavras da autora, uma não menos complexa estrutura geológica, oriunda do Pré-Cambriano, marcada por antigas falhas e dobramentos.

É preciso sempre ressaltar que os dados foram gerados em escalas cartográficas pequenas, que generalizam os elementos morfométricos do relevo. Contudo, numa escala de análise regional, esses dados demonstram uma clara predominância dos relevos planos nos territórios de Goiás e do Distrito Federal. Esse é um forte indicador da facilidade de acesso e, portanto, de sua ocupação. Aliado a outros fatores fisiográficos, históricos e econômicos, o relevo teve papel significativo na transformação porque passou essa região nas últimas décadas, quando sua cobertura vegetal foi radicalmente modificada, com o Cerrado e as florestas cedendo espaço para as pastagens e as lavouras.

\section{0 uso da terra e a cobertura vegetal contemporânea}

O mapa da Figura 6 é revelador do grau de modificação nas paisagens de Goiás e do Distrito Federal. Esse mapeamento foi realizado pelo Projeto de Identificação de Áreas Prioritárias para Conservação em Goiás 
(PDIAP), na escala original de 1:250.000, com base na classificação e interpretação visual de imagens Landsat 5 TM. Os autores optaram pela terminologia utilizada pelo Radambrasil para a identificação das classes de vegetação remanescente.

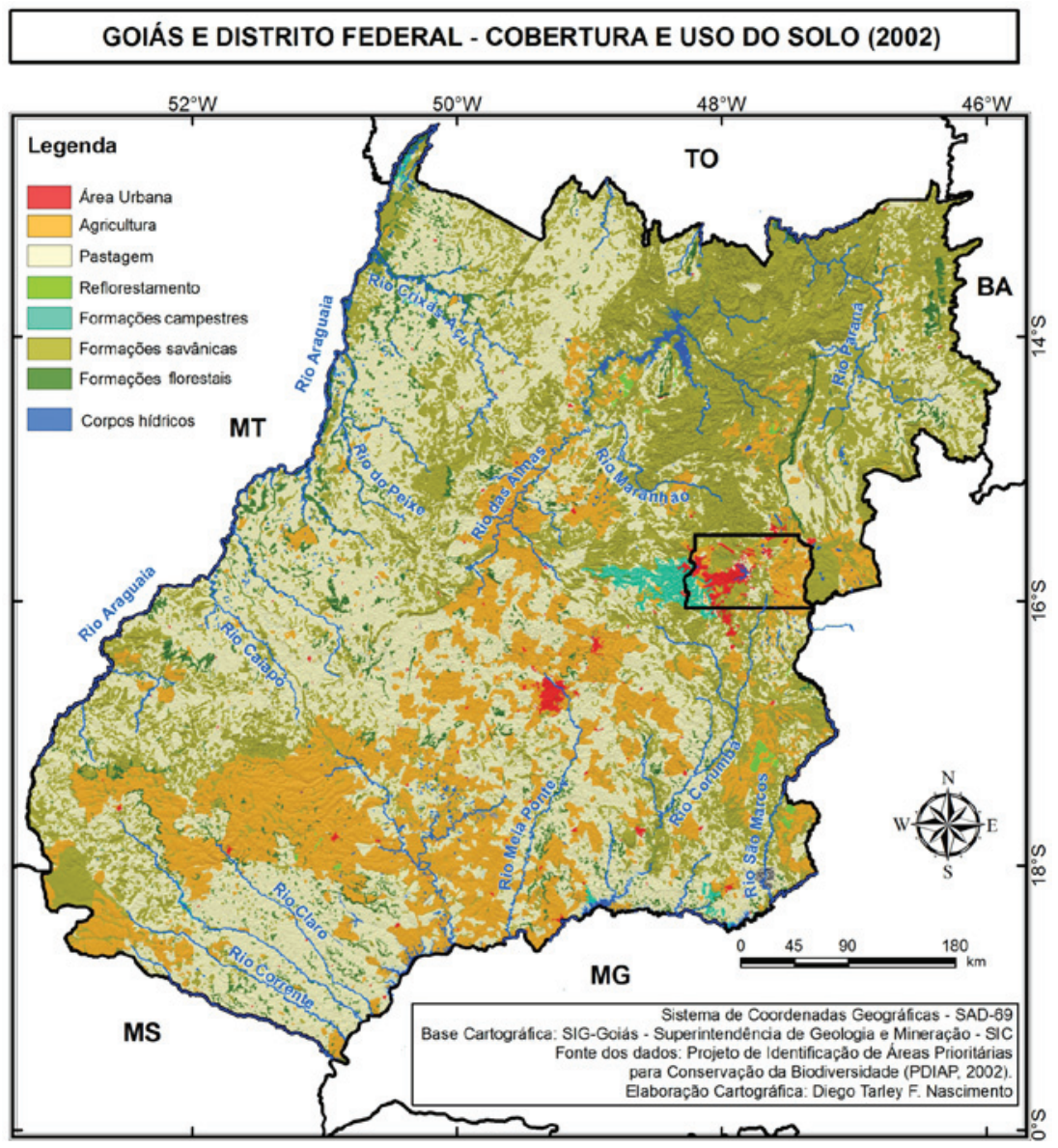

Figura 6 - Mapa de cobertura e uso do solo no estado de Goiás e Distrito Federal, em 2002.

A situação contemporânea da cobertura vegetal no estado de Goiás e no Distrito Federal é verdadeiramente preocupante, na medida em que se observa que a maior parte das terras foi incorporada por atividades 
econômicas e os remanescentes da vegetação original restaram, na sua maioria, como fragmentos pequenos e dispersos, incapazes de preservar a biodiversidade natural. A Tabela 4 apresenta o cálculo da área ocupada pelos tipos de vegetação e de uso da terra no território de Goiás e do Distrito Federal no ano de 2002.

Tabela 4 - Estado de Goiás e Distrito Federal - Cobertura vegetal e uso da terra - 2002.

\begin{tabular}{l|r|r}
\hline Tipo de vegetação ou uso da terra & Área em $\mathrm{km}^{2}$ & \% da área total \\
\hline Savana Florestada & $7.628,18$ & 2,21 \\
Savana Arbórea & $70.051,02$ & 20,25 \\
Savana Gramíneo-Lenhosa & $2.370,97$ & 0,69 \\
Savana Parque & $36.152,79$ & 10,45 \\
\hline Floresta Estacional Decidual & $1.355,34$ & 0,39 \\
Floresta Estacional Semidecidual & $5.487,06$ & 1,59 \\
Formações pioneiras & 54,72 & 0,02 \\
\hline Agricultura & $62.811,91$ & 18,16 \\
Pastagem & $154.724,64$ & 44,73 \\
Reflorestamento & 545,31 & 0,16 \\
\hline Áreas urbanas & $2.433,66$ & 0,70 \\
Corpos hídricos e outros (sem vegetação) & $2.274,40$ & 0,66 \\
\hline Total & $345.890,00$ & 100,00 \\
\hline
\end{tabular}

Fonte: Cálculo realizado em SIG, com base na reclassificação de dados do PDIAP.

Pelos dados apresentados, observa-se a absurda retração da vegetação nativa. A área de Cerrado (Savana), que antes cobria mais de $55 \%$ do território, foi reduzida para cerca de um terço. Contudo, esses poucos mais de 33\% incorporam, no levantamento referido, os tipos classificados no mapa da vegetação original como áreas de tensão ecológica. Boa parte desses remanescentes também é utilizada para o manejo do gado em criação extensiva, o que significa dizer que sua preservação não apresenta qualquer garantia de sucesso a longo ou médio prazo, à exceção, espera-se, das áreas que hoje constituem unidades de conservação, como os parques nacionais e estaduais.

Além disso, o desmatamento das formações florestais foi ainda mais brutal. As poucas ilhas ou os poucos corredores com esse tipo de vegetação representavam, em 2002, apenas 17\% da área originalmente 
coberta pelas florestas; juntos, esses remanescentes representavam apenas $2 \%$ da área total de Goiás e Distrito Federal. Em muitos locais, nem mesmo as matas ciliares ou de galeria foram preservadas, em desrespeito claro à legislação ambiental.

Já as pastagens e as lavouras tornaram-se as fisionomias dominantes nas paisagens de Goiás e do Distrito Federal. Especialmente no caso das pastagens, que passaram a ocupar o lugar que outrora fora do Cerrado, a expansão ocorreu de forma disseminada, cedendo espaço apenas em locais de difícil acesso, como os relevos movimentados do norte-nordeste goiano, ou nos chapadões e em algumas áreas de terras mais férteis, onde a agricultura consolida sua presença.

O mapeamento mais atualizado sobre a ocupação de uso das terras em Goiás e no Distrito Federal foi produzido pelo Projeto de Monitoramento do Desmatamento dos Biomas Brasileiros (PMDBBS), referente ao ano de 2010. Baseia-se na atualização de um mapeamento realizado em 2002, pelo Projeto de Conservação e Utilização Sustentável da Diversidade Biológica (PROBIO), segundo Sano et al. (2007), e infelizmente não apresenta distinção de classes nas áreas antropizadas. Comparada à situação de 2002 (Figura 7), é possível perceber que o desmatamento do Cerrado teve continuidade, embora num ritmo menos intenso.
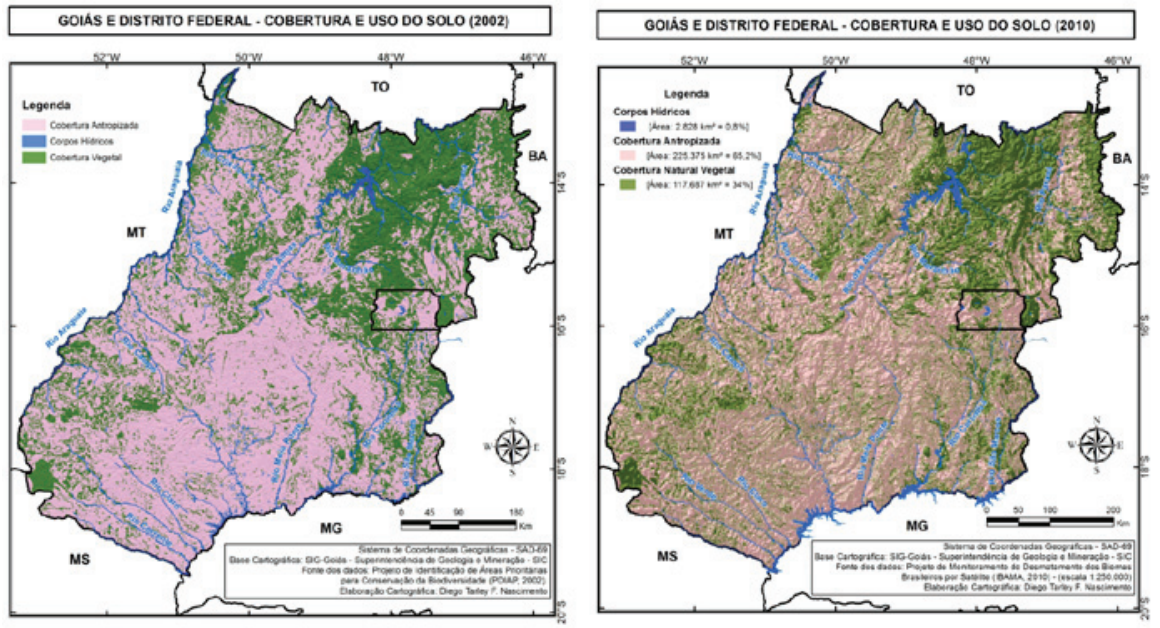

Figura 7 - Comparação entre os mapeamentos do PDIAP (2002) e do PMDBBS (2010). 
Comparando o mapa da Figura 1 e o das Figuras de 4 a 7, vê-se claramente como o relevo teve um papel significativo nesse quadro de transformações da cobertura vegetal em Goiás e no Distrito Federal. A Tabela 5 , que mostra o tipo de vegetação que originalmente recobria as diferentes faixas de declividade do relevo, exemplifica muito bem o motivo de ainda restarem trechos significativos do Cerrado na região norte de Goiás.

Tabela 5 - Estado de Goiás e Distrito Federal - Relação entre a declividade e a vegetação original.

\begin{tabular}{|c|c|c|c|c|c|c|}
\hline \multirow{3}{*}{$\begin{array}{c}\text { Faixas de } \\
\text { declividade }\end{array}$} & \multicolumn{6}{|c|}{ Classes de vegetação } \\
\hline & \multicolumn{2}{|c|}{ Cerrado } & \multicolumn{2}{|c|}{ Florestas } & \multicolumn{2}{|c|}{ Transição } \\
\hline & $\mathbf{k m}^{2}$ & $\%$ & $\mathbf{k m}^{2}$ & $\%$ & $\mathbf{k m}^{2}$ & $\%$ \\
\hline 0 a $3 \%$ & $152.448,50$ & 54,73 & $32.541,75$ & 11,68 & $92.196,75$ & 33,10 \\
\hline 3 a $8 \%$ & $23.130,75$ & 56,48 & $5.814,00$ & 14,2 & $11.964,00$ & 29,21 \\
\hline 8 a $20 \%$ & $12.805,25$ & 61,14 & $2.081,00$ & 9,94 & $6.044,00$ & 28,86 \\
\hline 20 а $45 \%$ & $3.778,50$ & 68,86 & 372,75 & 6,8 & $1.330,25$ & 24,24 \\
\hline 45 a $75 \%$ & 181,50 & 71,88 & 17,25 & 6,83 & 53,75 & 21,29 \\
\hline$>75 \%$ & 18,75 & 66,37 & 2,50 & 8,85 & 7,00 & 24,78 \\
\hline TOTAL & $192.363,25$ & - & $40.829,25$ & - & $111.595,75$ & - \\
\hline
\end{tabular}

Obs.: As porcentagens referem-se à parcela da faixa de declividade recoberta por determinado tipo de vegetação. A diferença em relação à área total das UF deve-se ao tamanho das células utilizadas nas matrizes de cruzamento $(500 \times 500 \mathrm{~m})$ e à exclusão de outras coberturas.

Nota-se, pela tabela, que as maiores faixas de declividade (acima de $20 \%$ ) eram recobertas predominantemente pelo Cerrado em suas diferentes fisionomias. Em torno de 70\% dessas áreas apresentavam algum tipo de Cerrado, enquanto 1/4 delas era domínio da vegetação de transição (tensão ecológica) entre o Cerrado e as florestas. Isso é exatamente o que ocorre no norte goiano, região das maiores elevações altimétricas, onde se vislumbram as manchas mais expressivas de declividades acentuadas, (conforme abordado anteriormente) e onde aparecem os maiores espaços contínuos ainda recobertos de Cerrado (Figura 6). Embora não se possa desconsiderar o fato de que o processo histórico de ocupação do território fora mais intenso na porção meridional de Goiás, dada a dinâmica de articulação com a área core do desenvolvimento econômico brasileiro (Região Sudeste), deve-se reconhecer que as dificuldades impostas pelo relevo permitiram a preservação da vegetação de Cerrado na sua porção setentrional.

Com relação à Floresta Estacional, dela restaram apenas corredores ao longo de algumas drenagens, especialmente na região das baixas alti- 
tudes e dos terrenos extremamente planos da Depressão do Araguaia, área de domínio da pecuária extensiva. É provável que essa preservação esteja ligada às faixas de inundação dos tributários do rio Araguaia, visto que são áreas conectadas ao curso médio do rio, que forma, a jusante, a planície do Bananal. Outras faixas expressivas estão associadas às encostas de escarpas, como no Vão do Paranã, em que a declividade acentuada tem dificultado a incorporação das terras pelas atividades econômicas.

As terras férteis foram, também, um atrativo muito forte para o avanço da agropecuária sobre a Floresta Estacional. Isso é bem visível no local que outrora fora ocupado pelo chamado "Mato Grosso de Goiás", que compunha uma extensa floresta na região central de Goiás (Figura 1), da qual restaram apenas fragmentos dispersos.

As áreas com relevo extremamente favorável, como o é caso dos chapadões do sudoeste de Goiás e extensos trechos do oeste do Distrito Federal, permitiram o desbaste quase total do Cerrado ou das florestas para o cultivo das lavouras (Figura 6). Por se tratar de uma agricultura eminentemente comercial, em geral voltada para a exportação, com exigência do aporte de grande volume de recursos, as propriedades são quase sempre de grandes dimensões, com pouca variedade na escolha do tipo de cultivo (tradicionalmente, a soja e o milho; e, mais recentemente, a cana-de-açúcar). O maior problema desses locais é que a aplicação intensa de biocidas exige o desmate de imensas áreas, sem que muitas vezes não seja respeitada sequer a preservação exigida por lei, como as margens de rios e as bordas de nascentes.

\section{Considerações finais}

O estado de Goiás apresentou, nos últimos anos, especialmente a partir de 2000, um grande avanço no uso das chamadas geotecnologias, sobretudo pelo governo estadual. Esse fato tem favorecido o desenvolvimento da produção cartográfica sobre o estado, envolvendo desde a aquisição e o processamento de imagens de satélite, até o uso cada vez mais expressivo de sistemas de informações geográficas e a construção e manutenção de bases de dados georreferenciados. Boa parte dessa tecnologia é voltada para a geração de renda para o Estado, como no controle da produção agrícola. Contudo, os órgãos ambientais também têm demonstrado um interesse crescente por seu uso, como meio de facilitar as atividades 
de reconhecimento das características geoambientais do estado e também a gestão dos sistemas naturais. Como exemplo, pode-se citar o projeto Áreas prioritárias para conservação em Goiás desenvolvido pela Agência Ambiental (Scaramuzza et al., 2005). Infelizmente, seus resultados não redundaram em políticas públicas ambientais consolidadas.

Nesse sentido, as bases de dados cartográficos que vêm sendo aglutinadas no site da Secretaria de Planejamento do Estado de Goiás (www. sieg.go.gov.br) são hoje uma vasta fonte para trabalhos geográficos sobre o estado e representam uma grande contribuição do governo estadual para a difusão desses conhecimentos. As relações entre essas fontes cartográficas devem permitir estudos mais aprofundados acerca dos elementos abordados neste artigo, cujos resultados, como já foi destacado, são generalizados em virtude da escala cartográfica (pequena) e da escala de análise (regional) utilizadas na abordagem de tais temas.

\section{Agradecimentos}

Meus agradecimentos a Diego Tarley Ferreira Nascimento, que gentilmente elaborou os mapas utilizados no artigo, em substituição aos da versão original.

\section{Notas}

1. Este texto se origina de um capítulo de livro (Oliveira, 2005), esgotado, com revisão de algumas informações, atualização de dados e substituição dos mapas e das demais ilustrações.

\section{Referências}

AB'SABER, Aziz N. A organização natural das paisagens inter e subtropicais brasileiras. In: SIMPÓSIO SOBRE O CERRADO, 3, 1971, São Paulo. Anais... São Paulo: Edgard Blücher/Ed. USP, 1971. p. 1-14.

AB'SABER, Aziz N.; COSTA JÚNIOR, Miguel. Contribuição ao estudo do sudoeste goiano. Boletim Paulista de Geografia, São Paulo, v. 4, n. 2, p. 3-26, 1950.

ALHO, Cleber J. R. Distribuição da fauna num gradiente de recursos em mosaico. In: NOVAES PINTO, Maria (Org.). Cerrado: caracterização, ocupação e perspectivas. 2. ed. Brasília: Ed. UnB, 1993. 681 p. 
ALHO, Cleber J. R.; MARTINS, E. de S. (Eds.). De grão em grão, o cerrado perde espaço. Brasília: WWF, 1995. 66 p.

ARENS, Karl. O cerrado como vegetação oligotrófica. 224. Botânica, São Paulo, v. 15, p. 59-77, 1958.

BARBOSA, Altair S. Sistema biogeográfico do cerrado: alguns elementos para sua caracterização. Goiânia: Ed. UCG, 1996. 44 p. (Contribuições; 3)

CARVALHO, Fernanda Almeida Carvalho. A relação entre o uso da terra e o relevo em Goiás - 2003. Monografia (Bacharelado em Geografia) - Universidade Federal de Goiás, Instituto de Estudos Socioambientais. Goiânia, 2003. 60f.

CONTI, José B.; FURLAN, Sueli A. Geoecologia: o clima, os solos e a biota. In: ROSS, Jurandyr L. S. (Org.). Geografia do Brasil. São Paulo: Edusp, 1995.

COUTINHO, Leopoldo M. Aspectos do cerrado. Cerrado. Disponível em: <http:// www.eco.ib.usp.br/cerrado>. Acesso em: 10 jul. 2000.

. O cerrado e a ecologia do fogo. Revista Ciência Hoje, Rio de Janeiro, v. esp., p. 131-138, maio 1992.

DIAS, Braulio Ferreira de Souza. Conservação da natureza no cerrado brasileiro. In: NOVAES PINTO, Maria (Org.). Cerrado: caracterização, ocupação e perspectivas. 2. ed. Brasília: Ed. UnB, 1993. 681 p.

EITEN, George. Formas fisionômicas do cerrado. Revista Brasileira de Botânica, São Paulo, v. 2, p. 139-148, 1979.

.Vegetação do cerrado. In: NOVAES PINTO, Maria (Org.). Cerrado: caracterização, ocupação e perspectivas. 2. ed. Brasília: Ed. UnB, 1993. 681 p.

GOMES, Horieste; TEIXEIRA NETO, Antônio; BARBOSA, Altair Sales. 2. ed. rev. ampl. Geografia: Goiás-Tocantins. Goiânia: Ed. UFG, 2004. 270p.

IBGE. Instituto Brasileiro de Geografia e Estatística. Manual técnico da vegetação brasileira. 2. ed. rev. e ampl. Manuais técnicos em geociências, n. 1. Rio de Janeiro: IBGE, 2012. 275 p.

MAGNAGO, Heliomar; SILVA, Maria Terezinha M.; FONZAR, Benedicta Catharina. Vegetação: as regiões fitoecológicas, sua natureza e seus recursos econômicos. In: PROJETO RADAMBRASIL. Folha SE.22 Goiânia. Rio de Janeiro: 1983. 768 p. (Levantamento de Recursos Naturais, 31)

MAMEDE, Lindinalva. Compartimentação geomorfológica da Região Centro-Oeste. Boletim SBG-NCO, n. 16, jul. 1993.

NASCIMENTO, Maria Amélia L. S. do. Geomorfologia do estado de Goiás. Boletim Goiano de Geografia, Goiânia, v. 12, n. 1, p. 1-22, jan./dez. 1992.

NOVAES, Antonio S. S.; AMARAL FILHO, Zebino P. do; VIEIRA, Paulo César et al. Pedologia: levantamento exploratório de solos. In: PROJETO RADAMBRASIL. Folha SE.22 Goiânia. Rio de Janeiro: 1983. 768 p. (Levantamento de Recursos Naturais; 31).

OLIVEIRA, Ivanilton José de. Os chapadões de(s)cerrados: a vegetação, o relevo e o uso das terras em Goiás e no Distrito Federal. In: ALMEIDA, Maria Geralda de 
(Org.). Tantos Cerrados: múltiplas abordagens sobre a biogeodiversidade e singularidade sociocultural. Goiânia: Vieira, 2005. p. 177-204.

PEREIRA, Benedito A. S.; VENTUROLI, Fábio; CARVALHO, Fabrício A. Florestas estacionais no Cerrado: uma visão geral. Pesquisa Agropecuária Tropical, Goiânia, v. 41, n. 3, p. 446-455, jul./set. 2011.

RIBEIRO, José Felipe; WALTER, Bruno M. T. Fitofisionomias do bioma cerrado. In: SANO, Sueli M.; ALMEIDA, Semíramis P. de (Eds.). Cerrado: ambiente e flora. Planaltina: Embrapa-CPAC, 1998. 556 p.

. As principais fitofisionomias do bioma Cerrado. In: SANO, Sueli M.; ALMEIDA, Semíramis P.; RIBEIRO, José Felipe (Eds.). Cerrado: ecologia e flora. Brasília-DF: Embrapa Informação Tecnológica, 2008. p. 151-212.

SANO, Edson E.; ROSA, Roberto; BRITO, Jorge L.; FERREIRA JÚNIOR, Laerte G. Mapeamento de cobertura vegetal do bioma cerrado: estratégias e resultados. Planaltina: Embrapa Cerrados (Boletim de pesquisa), 2007.

SCARAMUZZA, C. A. de M.; MACHADO, R. B.; RODRIGUES, S. T.; RAMOS NETO, M. B.; PINAGÉ, E. R.; DINIZ FILHO, J. A. F. Áreas prioritárias para conservação da biodiversidade em Goiás. In: FERREIRA, L. G. (Ed.). Conservação da biodiversidade e sustentabilidade ambiental em Goiás: prioridades, estratégias e perspectivas. Goiânia: 2005. 192 p. (No prelo).

WALTER, Bruno M. T.; CARVALHO, Arminda M.; RIBEIRO, José Felipe. As principais fitofisionomias do bioma Cerrado. In: SANO, Sueli M.; ALMEIDA, Semíramis P.; RIBEIRO, José Felipe (Eds.). Cerrado: ecologia e flora. Brasília: Embrapa Informação Tecnológica, 2008. p. 19-45.

Ivanilton José de Oliveira - Graduado em Administração de Empresas pela Faculdade Anhanguera de Ciências Humanas, Licenciado e Bacharel em Geografia pela Universidade Federal de Goiás, Mestre e Doutor em Geografia pela Universidade de São Paulo, Professor adjunto da Universidade Federal de Goiás.

Recebido para publicação em 7 maio de 2014 Aceito para publicação em 2 junho de 2014 